\title{
Engineered measles virus Edmonston strain used as a novel oncolytic viral system against human hepatoblastoma
}

\author{
Shu-Cheng Zhang ${ }^{1 *}$, Wei-Lin Wang ${ }^{1}$, Wei-Song Cai ${ }^{2}$, Kai-Lei Jiang ${ }^{1}$ and Zheng-Wei Yuan ${ }^{1}$
}

\begin{abstract}
Background: Hepatoblastoma (HB) is the most common primary, malignant pediatric liver tumor in children. The treatment results for affected children have markedly improved in recent decades. However, the prognosis for high-risk patients who have extrahepatic extensions, invasion of the large hepatic veins, distant metastases and very high alpha-fetoprotein (AFP) serum levels remains poor. There is an urgent need for the development of novel therapeutic approaches.

Methods: An attenuated strain of measles virus, derived from the Edmonston vaccine lineage, was genetically engineered to produce carcinoembryonic antigen (CEA). We investigated the antitumor potential of this novel viral agent against human HB both in vitro and in vivo.

Results: Infection of the Hep2G and HUH6 HB cell lines, at multiplicities of infection (MOls) ranging from 0.01 to 1 , resulted in a significant cytopathic effect consisting of extensive syncytia formation and massive cell death at 72-96 h after infection. Both of the HB lines overexpressed the measles virus receptor CD46 and supported robust viral replication, which correlated with CEA production. The efficacy of this approach in vivo was examined in murine Hep2G xenograft models. Flow cytometry assays indicated an apoptotic mechanism of cell death. Intratumoral administration of MV-CEA resulted in statistically significant delay of tumor growth and prolongation of survival.

Conclusions: The engineered measles virus Edmonston strain MV-CEA has potent therapeutic efficacy against HB cell lines and xenografts. Trackable measles virus derivatives merit further exploration in HB treatment.
\end{abstract}

Keywords: Hepatoblastoma, Oncolytic, Measles virus Edmonston strain, CD46

\section{Background}

Hepatoblastoma (HB) is the most common primary, malignant liver tumor in children with an incidence of $0.7-1$ case per million children [1-4]. The median age at diagnosis is 18 months; only $5 \%$ of the tumors are diagnosed after 4 years of age [5].

Although treatment strategies against HB have been established, they are constantly evaluated and revised through cooperative study groups worldwide [6-8]. The treatment results for affected children have markedly improved over the last decades due to the evolution of therapy from consisting of surgery alone to involving a

\footnotetext{
*Correspondence: zhangshucheng76@126.com

'Department of Pediatric Surgery, Major Laboratory of Chinese Health Ministry for Congenital Malformations, Shengjing Hospital of China Medical University, 36 Sanhao Street Heping District, Shenyang 110004, P.R. China Full list of author information is available at the end of the article
}

multimodal approach that combines adjuvant chemotherapy regimens and surgery. Recent international clinical studies have focused on the risk-adapted treatment of standard-risk patients with potentially resectable tumors and high-risk patients with unresectable tumors associated with extrahepatic extensions, invasion of the large hepatic veins, distant metastases and very high alpha-fetoprotein (AFP) serum-levels [2-4]. To date, about $92 \%$ of the patients in the standard-risk group can be cured by combining neo-adjuvant chemotherapy and surgery, whereas approximately $60 \%$ of all high-risk patients survive [2-4]. One problem that is especially present in the latter group is multidrug resistance after a number of chemotherapy courses $[1,5]$. Thus, the implementation of new, efficient drugs into future therapeutic regimens is especially critical.

\section{C) Bïomed Central}

(c) 2012 Zhang et al.; licensee BioMed Central Ltd. This is an Open Access article distributed under the terms of the Creative Commons Attribution License (http://creativecommons.org/licenses/by/2.0), which permits unrestricted use, distribution, and reproduction in any medium, provided the original work is properly cited. 
Oncolytic therapy, which uses replication-competent viruses that replicate in the tumor cells and kill the cells lytically has limited side effects. This therapy has shown great potential in the treatment of multiple tumors such as lymphoma, ovarian cancer, mesothelioma, breast cancer, renal and hepatocellular carcinoma [9-15]. A large variety of oncolytic viruses have been engineered [16-22]. Among the many oncolytic virus systems, the attenuated Edmonston vaccine strain of the measles virus (MV-Edm) has proven safe and effective [23-27]. It exerts its cytopathic effect (CPE) by fusing infected cells with the surrounding cells, forming multinucleated syncytia, which is followed by cell death by apoptotic or nonapoptotic mechanisms $[24,26,28] . M V$ is a negative-strand RNA paramyxovirus, and it has been shown that MV-Edm preferentially fuses and kills cells overexpressing the CD46 receptor [29]. CD46 is a membrane-associated complement regulatory protein that is ubiquitously expressed on nucleated human cells [30,31]. Tumor cells frequently overexpress CD46 [32]. These mechanisms contribute to the tumor selectivity of MV-Edm.

In contrast to the wild-type virus, which can cause a potentially serious disease, the vaccine and the Edmonston strains of the measles virus have an excellent safety record, with millions of administered vaccine doses that have significantly decreased the incidence, morbidity and mortality of measles worldwide [33]. Another advantage of using the MV-Edm as a vector is that the virus may be effectively engineered to express soluble marker peptides, such as CEA and beta-HCG, which may be employed as real-time correlates of viral gene expression in vivo. Furthermore, this virus expresses membrane proteins, such as the sodium iodine symporter, which allows for radionuclide imaging-based assessment of the viral localization and spread over time [33,34]. The serum CEA level has been used as an effective surrogate of the viral gene expression, which correlates with viral growth both in vivo and in vitro [33]. The detection of CEA in serum is widely available through clinical assays. Therefore, measuring the serum CEA is a cost-effective method for monitoring viral gene expression after MV-CEA treatment. Furthermore, this method allows for repeated measurements with minimal risk to the patient.

In the current study, we evaluated the efficacy of recombinant MV-Edm that expresses the soluble extracellular N-terminal domain of human CEA (MV-CEA) against human $\mathrm{HB}$ cell lines and xenografts.

\section{Methods}

\section{Cell culture}

The human HB cell line Hep2G was obtained from the American Type Culture Collection (ATCC; Manassas, VA) and maintained in modified Eagle's medium (MEM) supplemented with $10 \%$ heat-inactivated fetal bovine serum (FBS) and 1\% sodium pyruvate. The HUH6 cell line was kindly denoted by Professor Cai from the China Medical University. The normal human liver cell line L-02 was obtained from ATCC and maintained in MEM supplemented with $10 \%$ heat-inactivated fetal bovine serum (Sigma, Steinheim, Germany). The Vero African green monkey kidney cells (ATCC, CCL-81) used for the production of MV were maintained in DMEM supplemented with $5 \%$ FBS. All media used in this study contained $100 \mathrm{U} / \mathrm{ml}$ penicillin-streptomycin. Growth media, sera, and supplements were obtained from Gibco BRL (Grand Island, NY). All cells used in this study were cultured in a humidified atmosphere of $5 \% \mathrm{CO}_{2}$ at $37^{\circ} \mathrm{C}$.

\section{Viruses and infection assays}

The construction of MV-CEA was carried out in our laboratory as described previously [33]. The reverse genetics system, described by Radecke was employed [35]. In summary, the NSe strain c-DNA infectious clone (derived from the MV-Edm vaccine lineage Seed B) [36] was engineered by inserting the human CEA gene upstream of the MV $N$ gene. The titers of viral stocks were determined by $50 \%$ endpoint dilution assays (TCID 50) on Vero cells. For virus infection assays, $2 \times 10^{5}$ cells were incubated with recombinant MV-Edm was diluted in $1.0 \mathrm{ml}$ of Opti-MEM (Life Technologies, Inc. Shanghai, China) for 2 hours at $37^{\circ} \mathrm{C}$. At the end of the incubation period, the virus was removed, and the cells were maintained in standard medium.

\section{Evaluation of CPEs in vitro}

The Hep2G, HUH6 and L-02 cell lines were cultured in 24-well plates at a density of $2 \times 10^{5}$ cells/well. The cells were infected with MV-CEA at a multiplicity of infection (MOI) of 1 or 0.1 in $0.2 \mathrm{ml}$ of Opti-MEMI (GIBCO, Invitrogen, Shanghai, China) for 2 hours. The virus suspension was removed, and $1 \mathrm{ml}$ of fresh medium was added to each well. At 96 hours after infection, the cells were gently washed twice with phosphate buffered saline (PBS), and the remaining cells were fixed with $0.5 \%$ glutaraldehyde in PBS for 15 minutes. Then, the cells were washed with PBS and stained with $0.1 \%$ crystal violet solubilized in $2 \%$ ethanol-distilled water. The stained product was subsequently washed twice with distilled water, air-dried, and then photographed.

\section{Cell proliferation assay}

The Cell-Titer 96 Aqueous Non-Radioactive Cell Proliferation Assay (Promega, Madison, WI) was used in this study. Hep2G, HUH6 and L-02 cell lines were plated in 96-well plates at a density of $1 \times 10^{5}$ cells/well. Twelve hours after seeding, the cells were infected with MV-CEA at an MOI of 0.1 for different time intervals and then incubated with $20 \mu \mathrm{l}$ of the methanethiosulfonate (MTS) 
reagent for 2 hours at $37^{\circ} \mathrm{C}$. The absorbance at $490 \mathrm{~nm}$ was recorded using an enzyme-linked immunosorbent assay (ELISA) plate reader.

\section{Assessment of MV replication in human HB cells}

Cells from the human Hep2G, HUH6 and L-02 cell lines were seeded in 6-well plates at a density of $2.0 \times 10^{5}$ cells/well. Twelve hours after plating, the cells were infected with each MV at an MOI of 0.1 in Opti-MEM I. The cells and supernatants were collected at different time intervals. The viruses were released by two cycles of freezing and thawing. The viral titers in the cells and supernatants were determined by CEA detection using a CEA ELISA kit (PBL Biomedical Laboratories) as per the manufacturer's instructions.

\section{CEA analysis}

For the in vivo experiments, blood samples were collected from mice by retro-orbital bleeding, and the serum was analyzed to determine the CEA concentration. For the in vitro experiments, the supernatant from the MV-CEA-infected and uninfected HB cells was collected and analyzed to determine the CEA concentration. The ELISA specific for CEA was performed using an ELISA kit (PBL Biomedical Laboratories) as per the manufacturer's instructions.

\section{In vivo experiments}

All procedures involving animals were approved by and performed according to guidelines of the Institutional Animal Care and Use Committee of the China Medical University. A 27-gauge needle was used to subcutaneously inject nude mice (purchased from the laboratory animal center of the China Medical University) with $5 \times 10^{6}$ Hep2G cells $/ 100 \mu \mathrm{L}$ PBS in the right flank. Mice were examined daily for tumor growth. Tumor length, width, and height were measured with calipers. Tumor volume was calculated according to the formula width $\times$ width $\times$ height $/ 2$. When tumors reached a maximum diameter of $0.5 \mathrm{~cm}$, the MV-CEA and UV-inactivated MV-CEA treatments were initiated by intratumoral injection ( $n=8$ each group). Animals were euthanized when the tumor diameter reached $1 \mathrm{~cm}$ or when $20 \%$ of the body weight was lost.

\section{Flow cytometry}

The CD46 expression and the number of cells that died by apoptosis were determined by flow cytometry. To measure the CD46 expression, the cells were harvested with Cell Dissociation Buffer (GIBCO, Invitrogen), washed twice with PBS and incubated with a fluorescein isothiocyanate-labeled monoclonal mouse antihuman CD46, nectin 4 or isotype control antibodies (BD Biosciences, Pharmingen, US) for 1 hour on ice. The cells were washed twice with PBS. The cells were analyzed (10,000 cells per sample) using a FACScan (BD Biosciences, San Jose, CA). For the in vitro apoptosis assays, $\mathrm{HB}$ cells were plated in 6-well plates and treated with MV-CEA at an MOI of 0.1. Adherent and detached cells were harvested at 24, 48 and 72 hours after infection by centrifugation $(1000 \mathrm{rpm})$ and were washed twice with cold PBS. The cell pellet was re-suspended in $1 \times$ binding buffer at a concentration of $1 \times 10^{6}$ cells $/ \mathrm{ml}$. A total of $100 \mu \mathrm{l}$ of the cell suspension was transferred into a flow cytometry tube. In the next step, $5 \mu \mathrm{l}$ Annexin V-FITC and $10 \mu \mathrm{l}$ PI were added into the cell suspension followed by gentle vortexing. The cells were incubated at room temperature for 15 minutes in the dark. An additional $400 \mu \mathrm{l}$ of $1 \times$ binding buffer was added to each tube. Finally, the cells were analyzed using cell Quest software (BD Biosciences, San Jose, CA). All cells were made within the scope of the axes, and the gates were then set by drawing boundaries around the crowded subsets with $10^{5}$ cells that had an FSC-height $>200$ selected.

\section{Western blot analysis and ELISA}

Infected cells were harvested and solubilized in a Noni-

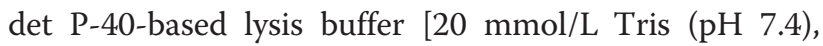
$250 \mathrm{mmol} / \mathrm{L} \mathrm{NaCl}, 1 \%$ Nonidet P-40, $1 \mathrm{mmol} / \mathrm{L}$ EDTA, $50 \mathrm{mg} / \mathrm{ml}$ leupeptin, and $1 \mathrm{mmol} / \mathrm{L}$ phenylmethylsulfonyl fluoride]. After incubating the cells on ice for $5 \mathrm{~min}$ utes, the cell lysates were clarified by centrifugation at $13,000 \mathrm{~g}$ for 30 minutes at $4^{\circ} \mathrm{C}$. The protein concentrations in the lysates were quantified using the Multiskan spectrum (Thermo Scientific, Finland). The samples were separated on precast 4-12\% gradient MOPS polyacrylamide gels (NOVEX, San Diego, CA) and then transferred to nitrocellulose membranes (BIO-RAD, Hercules, CA). The membranes were pretreated with Tris-buffered saline (TBS) containing 5\% dry milk and $0.05 \%$ Triton X-100 (TBST) for 1 hour at room temperature and were then incubated with monoclonal antiproteolytic cleavage of the poly(ADPribose) polymerase (Biovision, Mountain View, CA) and rabbit anti-ßactin (CHEMICON International, Temecula, CA) antibodies for 1 hour at room temperature. After several washes in TBST, the membranes were probed with rabbit or mouse peroxidase-conjugated secondary antibodies (Santa Cruz Biotechnology, Santa Cruz, CA) at room temperature for 1 hour. After a final wash with TBST, the immune-reactivity of the blots was detected using an enhanced chemiluminescence detection system (Amersham, Piscataway, NJ).

\section{Statistical methods}

All the collected data were analyzed with SPSS13.0 software. The statistical analysis of the significance of the 
differences in survival between mice treated with recombinant MV-CEA and mice that did not receive MV-CEA was performed using the log-rank test in the JMP (John Macintosh Product) program. The analysis of flow cytometry apoptosis comparisons used t test. The significance level was set at $p<0.05$.

\section{Results}

\section{Overexpression of CD46 in human HB cells}

The expression of CD46 in the human HB cell lines, Hep2G and HUH6, and in the human normal liver cell line L-02 was analyzed by flow cytometry with a FITClabeled monoclonal antihuman CD46 antibody. Human HB cell lines express high levels of CD46 compared to the normal liver cell line L-02. The CD46 receptor was found in $90.82 \%$ of the Hep2G cells and $80.03 \%$ of the HUH6 cells. A relatively low level of $8.91 \%$ was demonstrated in L-02 (Figure 1).

\section{MV-CEA induces significant CPEs and exhibits an antitumor effect in human $\mathrm{HB}$ lines}

To determine the infectivity of the recombinant MVCEA in human HB cells, the HB cell lines Hep2G and HUH6 and the normal liver cell line L-02 were infected with MV-CEA at MOIs of 1, 0.1 and 0.01 for 96 hours and then stained with crystal violet. Cell viability after MV-CEA infection was determined using the Cell-Titer 96 Aqueous Non-Radioactive Cell Proliferation Assay. Analyses were performed every 24 hours for 96 hours. MV-CEA demonstrated dramatic CPEs in an MOIdependent manner. The CPEs appeared at 72 hours post infection with MV-CEA at an MOI of 0.1 in Hep2G and HUH6 cells. However, the normal liver cell line L-02 showed minimal CPEs after MV-CEA infection (Figure 2a).

Compared with the control, MV-CEA demonstrated a greater reduction in the proliferation of $\mathrm{Hep} 2 \mathrm{G}$ and HUH6 cells from 72 to 96 hours at an MOI of 0.1 . Reduction of viability was observed in the Hep2G and
HUH6 cells within 72 hours after infection. Seventy-two hours after infection, the viability of the Hep2G cells was reduced to $74.67 \%$ at an MOI of 0.1 and to $86.33 \%$ at an MOI of 0.01 . The HUH6 cells yielded similar results (Figure $2 \mathrm{~b}$ ).

\section{MV-CEA successfully replicates in human $\mathrm{HB}$ cell lines and induces cell lysis}

Hep2G, HUH6 and L-02 cells were plated on 6-well plates at a density of $2 \times 10^{5}$ cells/well. The cells were infected with MV-CEA at an MOI of 0.1, and the supernatants and cells were collected from 24 to 96 hours postinfection. The intracellular viruses were released by two cycles of freezing/thawing. CEA levels revealed a time-dependent increase in MV mRNA in Hep2G and HUH6 cells, but not in the L-02 cell line. The intracellular CEA level peaked at 72 hours postinfection in the Hep2G and HUH6 cell lines (Figure 3a). In the culture supernatant, the CEA level peaked at 84 hours post infection (Figure $3 \mathrm{~b}$ ).

\section{MV-CEA infection induces significant apoptosis in human $\mathrm{HB}$ cell lines}

Hep2G, HUH6 and L-02 cells were infected with MVCEA at an MOI of 0.1 and apoptotic cells, which also had Annexin V-FITC staining, were analyzed by propidium iodide staining and subsequent flow cytometry. Upon infection with MV-CEA, the number of apoptotic cells increased in a time-dependent manner. At an MOI of 0.1 , MV-CEA induced apoptosis in $7.67 \%$ and $15.8 \%$ of the Hep2G cells and $7.3 \%$ and $17.35 \%$ of the HUH6 cells at 48 and 72 hours, respectively. However, at the same MOI, MV-CEA induced apoptosis in fewer than $5 \%$ of the L-02 cells. The difference is statistically significant between HB and L02 group $(\mathrm{P}<0.05)$ but is not statistically significant between Hep2G and HUH6 cells $(P>0.05)$, indicating that MV-CEA induces significant apoptosis in human HB cells (Figure 4a,b). We further examined the poly(ADP-ribose) polymerase expression
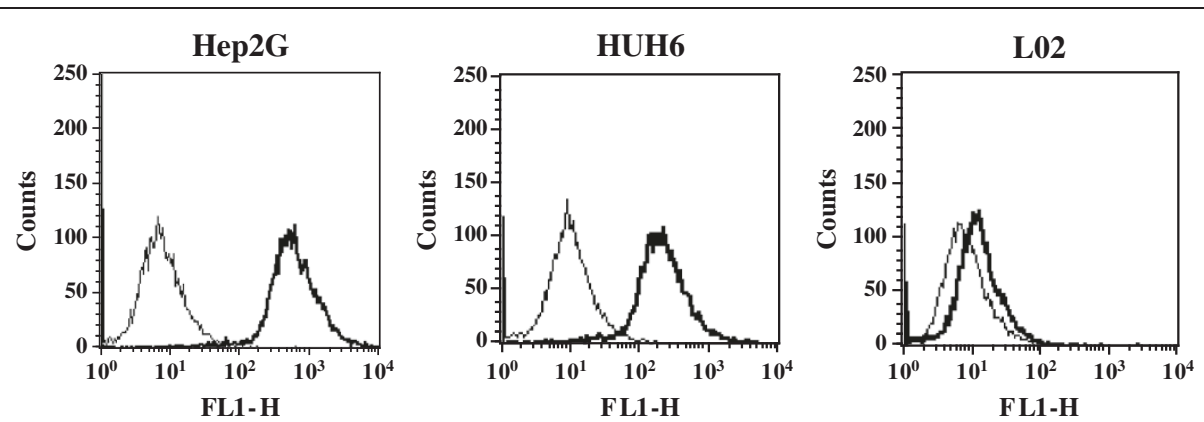

Figure 1 Expression of the CD46 receptor in human HB cells and a normal liver cell line. High levels of the CD46 receptor were observed in the human HB cell lines with the rate of $90.82 \%$ in Hep2G cells and $80.03 \%$ in HUH6 cells. A relatively low level of the CD46 receptor was detected in L-02 cells. Analyses were performed by flow cytometry using a monoclonal CD46 antibody. 
Figure 2 Infectivity, induction of syncytia, and CPE of MV-Edm in human HB cells. (a) Serial analysis to determine the CPE of recombinant MV-Edm was performed every 24 hours on the human $\mathrm{HB}$ cell lines Hep2G and HUH6 and normal liver cell line L-02. Seventy-two hours after infection at MOls of 0.1 and 1, the cells were stained with crystal violet representing viable, attached cells. (b) The time course of cell viability of the human $\mathrm{HB}$ cell lines Hep2G and HUH6 and normal liver cell line L-02 $(n=8)$ after infection with recombinant MV-Edm at MOls of 0.1 and 1 was analyzed using a Cell Titer 96 Aqueous nonradioactive cell proliferation assay kit. ${ }^{* * *}$ Group $\mathrm{MOI}=1.0$ versus Group $\mathrm{MOl}=0, \mathrm{P}<0.05$; **

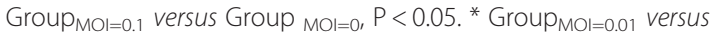
Group $\mathrm{MOI}=0, \mathrm{P}<0.05$.

and found that the $85-\mathrm{kd}$ cleaved poly(ADP-ribose) polymerase fragment was expressed in Hep2G cells at $48 \mathrm{~h}$ and $72 \mathrm{~h}$ after being infected with MV-CEA. This finding was in agreement with the FACS results (Figure 4c).

\section{Intratumoral administration of MV-CEA induces regression of $\mathrm{HB}$ xenografts and Can Be monitored by serial serum CEA concentrations}

To evaluate the potential use of recombinant MV-Edm for HB therapy, we first tested MV-CEA in a subcutaneous human HB xenograft model. Hep2G cells $\left(2 \times 10^{6}\right.$ cells/mouse) were implanted in the right flanks of nude mice. When the maximum tumor diameter measured approximately $0.5 \mathrm{~cm}$, each mouse was treated with a total of 5 doses of MV-CEA $\left(1.0 \times 10^{7}\right.$ TCID50) or an equivalent dose of UV-inactivated MV-CEA for 10 days (defined as untreated, $n=8$ per group). Serum CEA concentration, tumor volume, and survival curves are shown in Figure 5.

In the Hep2G xenograft models, the serum CEA concentrations could be detected as early as 4 days after initiating therapy; these concentrations increased over time. The CEA concentration reached its maximum on day 25 after the last viral dose. After reaching their maximum concentrations, the mean CEA levels started to decrease (Figure 5a). No CEA elevation was observed in the UV-inactivated MV-CEA-treated (defined as untreated) animals.

In the Hep2G cell line xenografts, the tumor-suppressive effect of MV-CEA first became apparent on day 7, and this therapeutic efficacy then increased over time, resulting in significant suppression of tumor growth and prolonged survival of treated animals (Figure 5b,c). The median survival of those treated with MV-CEA and of those treated with UV-inactivated MV-CEA was 72 and 25 days, respectively. The median survival of the MV-CEA-treated mice, with a 2.88 -fold increase compared to the control group, was significantly longer than that of the control group ( $\mathrm{P}<0.05$; Figure $5 \mathrm{c}$ ). All mice in the control group had to be euthanized on day 28. In the MV-CEA-treated group, complete tumor regression was observed in one-eighth of treated mice $(\mathrm{P}<0.05$; Figure $5 \mathrm{c})$. 

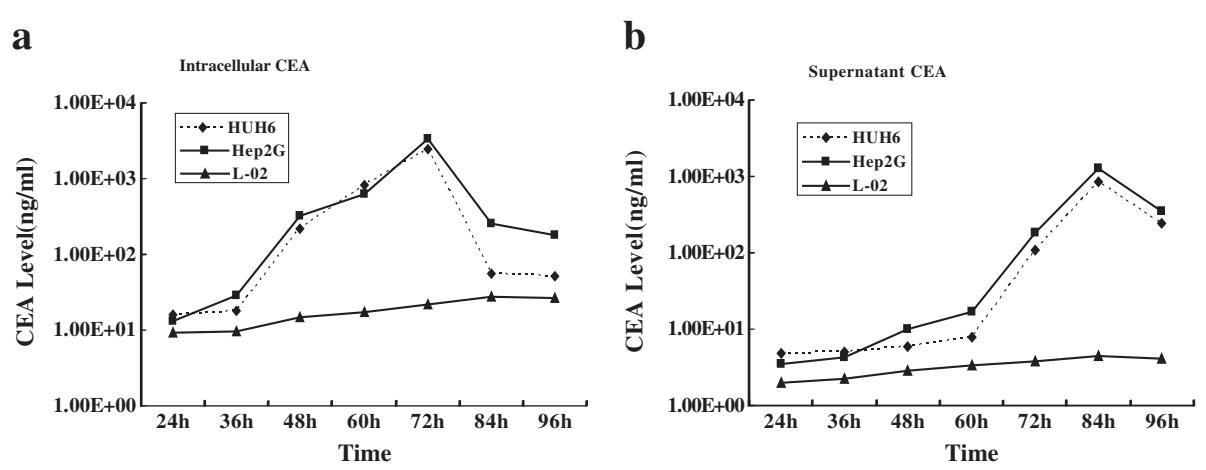

Figure 3 Replication of MV-CEA in human HB cells. CEA level of the (a) intracellular and (b) culture supernatant in the Hep2G cell line was detected by ELISA from 24 to 96 hours after infection at an MOI of 0.1. The intracellular CEA levels increased with time and peaked at 72 hours post infection, and the supernatant CEA level peaked at 84 hours post infection in Hep2G cells but not in L-02 cells. This phenomenon provides strong evidence for MV-CEA replication and cell lysis.

\section{Discussion}

Oncolytic therapy has reportedly excellent efficacy in the treatment of many tumors, such as lymphoma, ovarian cancer, mesothelioma, breast cancer and hepatocellular carcinoma [9-15].. Specifically, there are many advantages in using oncolytic therapy to treat liver malignancies; at some medical centers, oncolytic therapy has even been evaluated in clinical trials [37-39]. As a special subtype of hepatocellular carcinoma, HB originates from the liver embryonic tissues and has the potential for diverse differentiation. Many components, such as the epithelium, bone and cartilage, can be included within the tumor; as a result, HB differs from general hepatocellular carcinoma in its histological and the biological characteristics. Histologically, the tumors are divided into epithelial and mixed epithelial/mesenchymal subtypes. Tumor cells may appear with a wide variety of characteristics ranging from almost liver-cell-like to undifferentiated blastomal cells. The majority of $\mathrm{HB}$ cells are epithelial, consisting of embryonal and fetal cells. About $5 \%$ of the tumors belong to the small-cell undifferentiated subtype, which is associated with a worse prognosis $[5,40]$. Despite many advances in the use of oncolytic therapies for other liver malignancies, little is known about the use of oncolytic therapy in human HB. In this study, we report the potent therapeutic efficacy of oncolytic virus against human $\mathrm{HB}$ cells.

Currently, a large variety of oncolytic viruses are under evaluation in clinical trials [16-22]; the most common viruses tested are derived from the attenuated Edmonston vaccine strain of the measles virus [9-15], adenovirus $[16,17]$, herpes simplex virus (HSV) [18,19], Newcastle disease virus (NDV) [20], parvovirus [21], and poliovirus [22]. The present results demonstrate that virotherapeutics can be used safely and efficiently as cancer therapies. For safety reasons, vaccine virus-derived virotherapeutics are of special interest (e.g., measles vaccine virotherapeutics) because they are approved for human use, have been applied millions of times with a longstanding excellent safety record, and exhibit a potent natural oncolytic activity $[41,42]$. As one of the most tested vaccines, the attenuated Edmonston vaccine strain of the measles virus has been well reported in hepatocellular carcinoma but not in HB treatment. MV is a replicating virus; therefore, the MV-Edm vaccine strain derivatives of MV can offer the potential advantage of increased dissemination in the tumor and of potentially enhanced therapeutic benefit compared to non-replicating viral or non-viral vector systems.

The MV enters the cells through the interaction of the $\mathrm{H}$-glycoprotein with the MV receptors, CD150 (signaling lymphocyte-activation molecule, SLAM) and CD46 [41-43]. Of note, the wild-type measles virus enters more efficiently through the SLAM receptor, whereas the Edmonston vaccine strain of measles virus enters the cells predominantly through the CD46 receptor. The MV receptor CD46 (membrane cofactor protein) belongs to the family of membrane-associated complement regulatory proteins that serve as an important mechanism of self-protection against complementmediated lysis. Tumor cells frequently overexpress CD46. These mechanisms contribute to the tumor selectivity of MV-Edm. The effectiveness of MV-Edmmediated oncolysis is highly dependent upon the expression of the cellular attachment receptor CD46, which is expressed more frequently in human cancer cells than in normal cells. In this study, we have demonstrated that the measles virus vaccine strain derivative MV-CEA, which has been genetically engineered to produce CEA, has significant antitumor activity against $\mathrm{HB}$ as indicated by the CPE of MV-CEA on HB cell lines in vitro and the efficacy of MV-CEA in an HB xenograft model. Our data show that CD46 is overexpressed in HB cell lines compared to normal liver cells, and MV-CEA successfully 


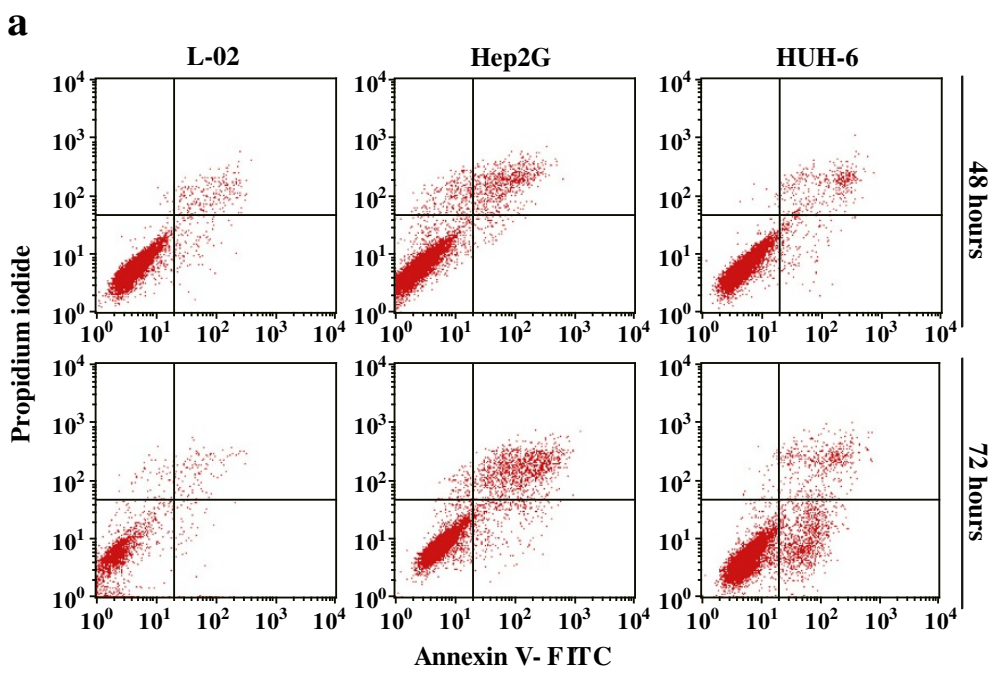

b

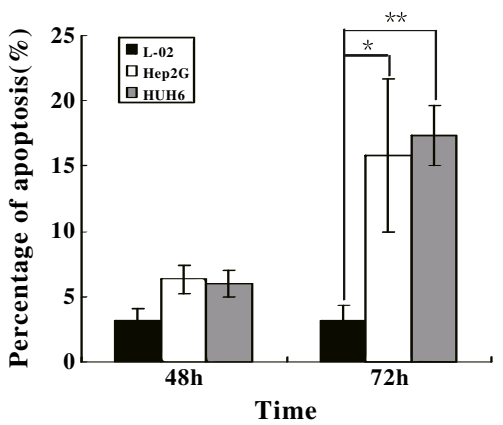

$$
\text { c }
$$

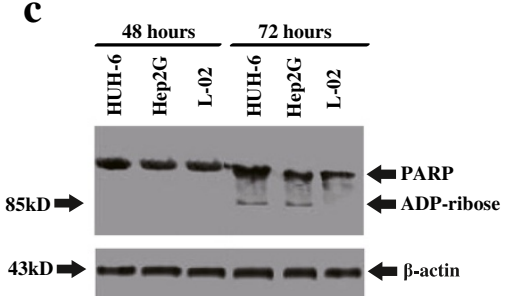

Figure 4 Apoptosis induced by MV-CEA in the human Hep2G and HUH6 cells. The cells were infected with MV-CEA at an MOI of 0.1 . Adherent and detached cells were harvested at 24, 48 and 72 hours post infection. (a) The percentage of apoptotic cells was measured by FACS and is shown in this figure. In the L-02 cells, there was no dramatic apoptosis, but the Hep2G cells demonstrated dramatic apoptosis at 72 hours postinfection. (b)The significant difference is significant between the HB and L-02 groups but not between the two HB cell lines. * Group Hep2G Versus Group L-02, $\mathrm{P}<0.01$; ${ }^{* *} \mathrm{Group}_{\text {HUH-6 }}$ Versus Group ${ }_{\mathrm{L}-02}, \mathrm{P}<0.01$. (c) We further examined the poly(ADP-ribose) polymerase expression by Western blot and found that the $85-\mathrm{kd}$ cleaved poly(ADP-ribose) polymerase fragment was expressed in the Hep2 $\mathrm{G}$ and $\mathrm{HUH}-6 \mathrm{cells}$ at $72 \mathrm{~h}$ after infection with MV-CEA. This finding was in agreement with the FACS results.

infected human $\mathrm{HB}$ cells, resulting in transgene expression, syncytium formation, and tumor cell killing; therefore, we conclude that $\mathrm{HB}$ fulfills the requirements for viral uptake and selective cell fusion and killing.

It is likely that additional factors contribute to the MV-Edm tumor selectivity. In 2011, two independent groups reported the identification of a novel MV-Edm receptor, nectin 4 [44-46]. It is a tumor cell marker found in breast, lung and ovarian carcinomas and rendered cells susceptible to the MV-Edm. The transient knockdown of nectin 4 with siRNA abolished the wildtype MV infection in these cell lines. Similar results were also confirmed in the MV-Edm. The binding of the V domain of nectin 4 to $\mathrm{MV}-\mathrm{H}$ has been considered a potential mechanism for the MV pathogenicity [44]. Also, a few studies have indicated that MV infection can occur via $\mathrm{CD} 147$ and virion-associated $\mathrm{CypB}$, independent of $\mathrm{MV}-\mathrm{H}$ [47]. Watanabe et al [47]. identified CypB as a 


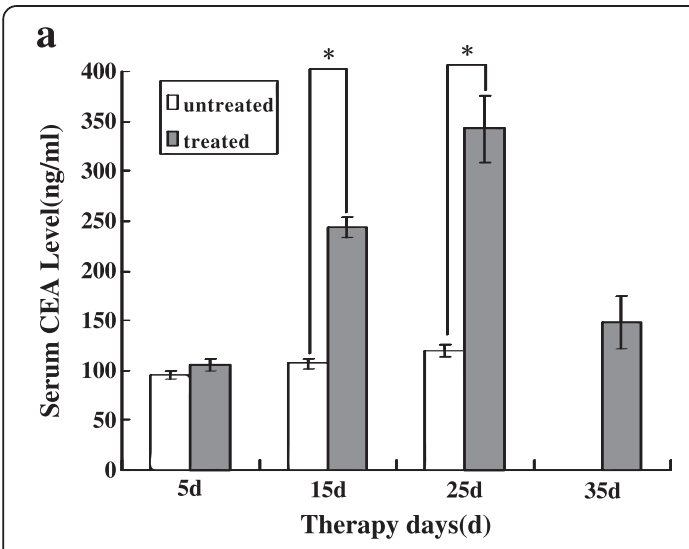

b

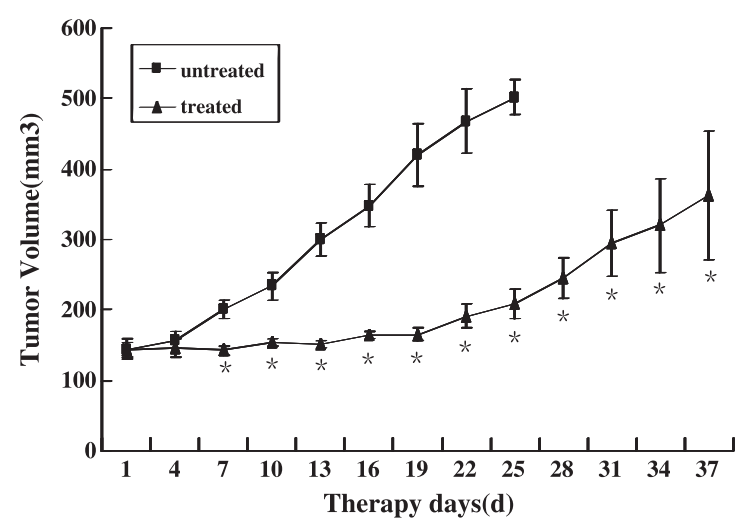

c

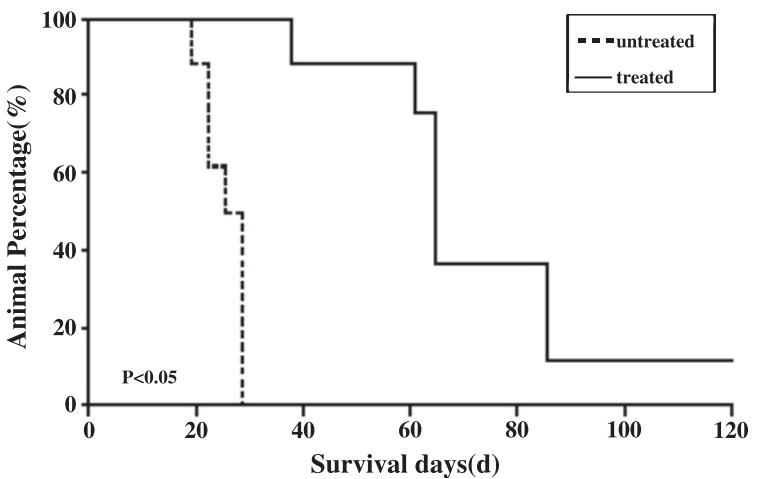

Figure $\mathbf{5}$ The serum CEA concentrations and tumor suppression after intratumoral MV-CEA therapy of human HB xenografts. Mice bearing $\mathrm{HB}$ xenografts (Hep2G) were injected intratumorally with $2 \times 10^{6}$ TCID50 of MV-CEA every other day a total of five times ( $1.0 \times 10^{7}$ total TCID50/mouse). Treatment groups ( $n=8$ per group) received active $M V-C E A$; the untreated group received

UV-inactivated MV-CEA. (a) The time course of serum CEA concentration in HB xenograft-bearing mice after MV-CEA therapy. *Group untreated versus Group treated, P<0.05; (b) The increase in tumor volume after initiation of the MV-CEA therapy. The data points are given as the median with positive standard error. ${ }^{*}$ Group untreated versus Group treated, $P<0.05$; (c) The Kaplan-Meier survival curves of the treated and untreated mice. The results show significant suppression of tumor growth in the MV-CEA treated animals $(p<0.05)$ and statistically significant prolongation of survival $(p<0.05)$. binding partner of MV-N and further showed that the wild-type MV recognizes CD147 as a receptor on epithelial cells via the $\mathrm{CypB}$ that is incorporated into the virus particles. It is still not clear whether other $\mathrm{MV}$ strains, such as the MV-Edm, share a similar pathway. Although a variety of other receptors including $\mathrm{H}$ protein dependent or independent ones can be used for MV-Edm infection, it has been reported that their efficiency is far lower than CD46 [46]. The CD46 receptor is still the main player for MV-Edm spreading between cells. Therefore, it is not necessary to detect all of the other receptors one by one when a high level of CD46 is sufficient for demonstrating the oncolytic mechanism.

MV-CEA resulted in a strong CPE in vitro and in vivo. In this study, two human $\mathrm{HB}$ cell lines, Hep2G and HUH6, were used. These two lines have features that are the most characteristic of human $\mathrm{HB}$ and have been widely used in HB-related investigations [40,48]. Although the $\mathrm{HB}$ subtype and the risk level (either standard-risk or high-risk) induced by these two lines are still not verified, it is not critical for the oncolytic virus to be used in the HB biotherapy. Only cells that express high levels of the CD46 receptor are infected by MV-Edm and lytically killed. This statement was verified in the present study; both of the tested cell lines were susceptible to the cytotoxic effect of MV-CEA but differed in their cell death kinetics. The Hep2G cells were eliminated very efficiently and quickly, whereas the cytotoxic effect of MV-CEA on the HUH6 cells was observed later. The HB cell lines used in our study showed variable susceptibility to the cytotoxic effect of MV-CEA, most likely resembling the situation in primary human tumors, which are composed of heterogeneous tumor cell populations [5]. Both cell lines express comparable levels of CD46 but differ in other aspects, such as their histological subtypes. Differences in the components of these two lines or other not-yetidentified factors in the process of measles-induced cytotoxicity could explain the differences in susceptibility.

As one of the most common causes of cell death, apoptosis has been well described in other malignancies. It has been reported that MV-Edm can induce apoptosis in both the tumor cells and the syncytia by a series of signal pathways, such as the Fas-associated death domain (FADD), protein kinase $\mathrm{C}$ (PKC), and the janus kinase-signal transducer and activator of transcription (JAK-STAT) signaling pathways $[49,50]$. Similarly, we have used a variety of techniques that demonstrate extensive apoptosis after infection of MV-Edm in human HB cell lines [26]. These results are in agreement with prior work that has indicated that apoptosis is the main mechanism of death for MV-induced syncytia [51]. The exact mechanism of cell death after MV-Edm-induced syncytium formation is still unknown and should be further investigated. 
One of the main advantages of MV-Edm therapy in human HB is that the tumor offers the possibility of localized treatments compared with other malignancies such as ovarian cancers, glioblastoma and prostate cancers. In most cases of $\mathrm{HB}$, the tumor is located within the liver and does not have distant metastases after regular chemotherapy; also, the tumor is easily accessible using ultrasound or computed tomography (CT) guidance. HB tumors can easily be localized and injected with a therapeutic agent. In any case, the presence of anti-MV antibodies is not expected to significantly decrease efficacy. In a mouse model in which mice received passive transfer of anti-MV antibodies, Grote et al. found that intratumoral MV-Edm therapy of human lymphoma xenografts resulted in effective tumor regression without compromise through the presence of anti-MV antibodies [52]. These findings were in accordance with the results of a study of intratumoral therapy with a retrovirus in immune-competent $\mathrm{C} 3 \mathrm{H}$ mice and of a clinical phase II study of a genetically modified adenovirus in patients with advanced head and neck cancer [53,54].

A major drawback of many cancer agents is the lack of convenient methods for monitoring the agent after administration to the patient. MV-Edm derivatives engineered to express CEA allow noninvasive tracking of the viral gene expression as well as localization of the infected tumor tissue. The advantage of this method has been well described in previous investigations [15,33]. In this study, the same result was verified in $\mathrm{HB}$ both in vitro and in vivo. Given the fact that Hep2G is known to intrinsically produce CEA, these cells themselves may be the source of the CEA, which would impact the serum CEA. However, the impact on the final result would be minor because all of the comparisons were carried out within the Hep2G groups instead of between the Hep2G and other groups. In addition, in the clinical practice, fewer than $10 \%$ of patients with HB can produce CEA and the amount is very little; it is likely unnecessary to worry about the confusion of intrinsic CEA.

\section{Conclusions}

MV-CEA has potent therapeutic efficacy against human $\mathrm{HB}$ both in vivo and in vitro. We therefore believe that, given their antitumor activity and potential for noninvasive monitoring, engineered trackable MV derivatives warrant further investigation for their use in HB treatment. These studies have not yet been translated into a clinical trial, but should provide the foundation for future clinical developments.

\section{Abbreviations}

(HB), Hepatoblastoma; (CEA), Carcinoembryonic antigen; (AFP), Alphafetoprotein; (MV-Edm), The attenuated Edmonston vaccine strain of the measles virus; (CPE), Cytopathic effect; (MOI), Multiplicity of infection.
Competing interests

The authors declare that they have no competing interests.

\section{Authors' contributions}

SCZ performed the expression of CD46 and oncolytic studies and drafted the manuscript. Wei-song CAl performed the apoptosis assays and the statistical analysis. KJ performed the in vivo studies. WLW participated in the design of the study. ZWY conceived of the study, participated in its design and coordination and helped to draft the manuscript. All authors read and approved the final manuscript.

\section{Acknowledgements}

All the work was performed in the Shengjing hospital of the China medical university, Shenyang, China P.R. the study was supported by the National Natural Science Foundation of China (No.30700917), and the paper was not presented in any meeting.

\section{Author details}

${ }^{1}$ Department of Pediatric Surgery, Major Laboratory of Chinese Health Ministry for Congenital Malformations, Shengjing Hospital of China Medical University, 36 Sanhao Street Heping District, Shenyang 110004, P.R. China. ${ }^{2}$ Department of Medical Oncology, Shengjing Hospital of China Medical University, 36 Sanhao Street Heping District, Shenyang 110004, P.R. China.

Received: 13 April 2012 Accepted: 23 September 2012

Published: 25 September 2012

\section{References}

1. von Schweinitz D: Management of liver tumors in childhood. Semin Pediatr Surg 2006, 15(1):17-24.

2. Häberle B, Bode U, von Schweinitz D: Differentiated treatment protocols for high- and standard-risk hepatoblastoma-an interim report of the German Liver Tumor Study HB99. Klin Padiatr 2003, 215(3):159-165.

3. Perilongo G, Maibach R, Shafford E, Brugieres L, Brock P, Morland B, et al: Cisplatin versus cisplatin plus doxorubicin for standard-risk hepatoblastoma. N Engl J Med 2009, 361(17):1662-1670.

4. Zsíros J, Maibach R, Shafford E, Brugieres L, Brock P, Czauderna P, et al: Successful treatment of childhood high-risk hepatoblastoma with dose-intensive multiagent chemotherapy and surgery: final results of the SIOPEL-3HR study. J Clin Oncol 2010, 28(15):2584-2590.

5. Litten JB, Tomlinson GE: Liver tumors in children. Oncologist 2008, 13(7):812-820.

6. Katzenstein HM, London WB, Douglass EC, et al: Treatment of unresectable and metastatic hepatoblastoma: a Pediatrc Oncology Group Phase II study. J Clin Oncol 2002, 20:3438-3444.

7. Fuchs J, Rydzynski J, von Schweinitz D, et al: Pretreatment prognostic factors and treatment results in children with hepatoblastoma: a report from the German Cooperative Pediatric Liver Tumor Study HB 94. Cancer 2002, 92:172-182.

8. Perilongo G, Shafford E, Maibach R, et al: Risk-adapted treatment for childhood hepatoblastoma. Final report of the second study of the International Society of Paediatric Oncology-SIOPEL 2. Eur J Cancer 2004, 40:411-421.

9. Peng KW, TenEyck CJ, Galanis E, Kalli KR, Hartmann LC, Russell SJ: Intraperitoneal therapy of ovarian cancer using an engineered measles virus. Cancer Res 2002, 62(16):4656-4662.

10. Heinzerling L, Künzi V, Oberholzer PA, Kündig T, Naim H, Dummer R: Oncolytic measles virus in cutaneous T-cell lymphomas mounts antitumor immune responses in vivo and targets interferon-resistant tumor cells. Blood 2005, 106:2287-2294.

11. Vidal L, Pandha HS, Yap TA, White CL, Twigger K, Vile RG, Melcher A, Coffey M, Harrington KJ, DeBono JS: A phase I study of intravenous oncolytic reovirus type 3 Dearing in patients with advanced cancer. Clin Cancer Res 2008, 14(21):7127-7137.

12. Haralambieva I, lankov I, Hasegawa K, Harvey M, Russell SJ, Peng KW: Engineering oncolytic measles virus to circumvent the intracellular innate immune response. Mol Ther 2007, 15(3):588-597.

13. Gauvrit A, Brandler S, Sapede-Peroz C, Boisgerault N, Tangy F, Gregoire M: Measles virus induces oncolysis of mesothelioma cells and allows dendritic cells to cross-prime tumor-specifc CD8 response. Cancer Res 2008, 68(12):4882-4892. 
14. McDonald CJ, Erlichman C, Ingle JN, Rosales GA, Allen C, Greiner SM, Harvey ME, Zollman PJ, Russell SJ, Galanis E: A measles virus vaccine strain derivative as a novel oncolytic agent against breast cancer. Breast Cancer Res Treat 2006, 99(2):177-184

15. Blechacz B, Splinter PL, Greiner S, Myers R, Peng KW, Federspiel MJ, Russell SJ, LaRusso NF: Engineered measles virus as a novel oncolytic viral therapy system for hepatocellular carcinoma. Hepatology 2006, 44(6):1465-1477.

16. García-Castro J, Alemany R, Cascalló M, Martínez-Quintanilla J, Arriero Mdel M, Lassaletta A, Madero L, Ramírez M: Treatment of metastatic neuroblastoma with systemic oncolytic virotherapy delivered by autologous mesenchymal stem cells: an exploratory study. Cancer Gene Ther 2010, 17(7):476-483.

17. Pesonen S, Helin H, Nokisalmi P, Escutenaire S, Ribacka C, Sarkioja M, Cerullo V, Guse K, Bauerschmitz G, Laasonen L, Kantola T, Ristimaki A, Rajecki M, Oksanen M, Haavisto E, Kanerva A, Joensuu T, Hemminki A: Oncolytic adenovirus treatment of a patient with refractory neuroblastoma. Acta Oncol 2010, 49(1):117-119.

18. Li H, Dutuor A, Tao L, Fu X, Zhang X: Virotherapy with a type 2 herpes simplex virus-derived oncolytic virus induces potent antitumor immunity against neuroblastoma. Clin Cancer Res 2007, 13(1):316-322.

19. Parikh NS, Currier MA, Mahller YY, Adams LC, Di Pasquale B, Collins MH, Cripe TP: Oncolytic herpes simplex virus mutants are more efficacious than wild-type adenovirus Type 5 for the treatment of high-risk neuroblastomas in preclinical models. Pediatr Blood Cancer 2005, 44(5):469-478.

20. Elankumaran S, Rockemann D, Samal SK: Newcastle disease virus exerts oncolysis by both intrinsic and extrinsic caspase-dependent pathways of cell death. J Virol 2006, 80(15):7522-7534

21. Lacroix J, Leuchs B, Li J, Hristov G, Deubzer HE, Kulozik AE, Rommelaere J, Schlehofer JR, Witt O: Parvovirus H1 selectively induces cytotoxic effects on human neuroblastoma cells. Int J Cancer 2010, 127(5):1230-1239.

22. Toyoda H, Yin J, Mueller S, Wimmer E, Cello J: Oncolytic treatment and cure of neuroblastoma by a novel attenuated poliovirus in a novel poliovirus-susceptible animal model. Cancer Res 2007, 67(6):2857-2864.

23. Dingli D, Peng KW, Harvey ME, Greipp PR, O'Connor MK, Cattaneo R, Morris $J C$, Russell SJ: Image-guided radiovirotherapy for multiple myeloma using a recombinant measles virus expressing the thyroidal sodium iodide symporter. Blood 2004, 103(5):1641-1646.

24. Peng KW, Ahmann GJ, Pham L, Greipp PR, Cattaneo R, Russell SJ: Systemic therapy of myeloma xenografts by an attenuated measles virus. Blood 2001, 98(7):2002-2007

25. Meng X, Nakamura T, Okazaki T, Inoue H, Takahashi A, Miyamoto S, Sakaguchi G, Eto M, Naito S, Takeda M, Yanagi Y, Tani K: Enhanced antitumor effects of an engineered measles virus Edmonston strain expressing the wild-type N, P, L genes on human renal cell carcinoma. Mol Ther 2010, 18(3):544-551.

26. Phuong LK, Allen C, Peng KW, Giannini C, Greiner S, TenEyck CJ, Mishra PK, Macura SI, Russell SJ, Galanis EC: Use of a vaccine strain of measles virus genetically engineered to produce carcinoembryonic antigen as a novel therapeutic agent against glioblastoma multiforme. Cancer Res 2003 63(10):2462-2469.

27. Grote D, Russell SJ, Cornu TI, Cattaneo R, Vile R, Poland GA, Fielding AK: Live attenuated measles virus induces regression of human lymphoma xenografts in immunodefiient mice. Blood 2001, 97(12):3746-3754.

28. Higuchi H, Bronk SF, Bateman A, Harrington K, Vile RG, Gores GJ: Viral fusogenic membrane glycoprotein expression causes syncytia formation with bioenergetic cell death: implications for gene therapy. Cancer Res 2000, 60(22):6396-6402.

29. Anderson BD, Nakamura T, Russell SJ, Peng KW: High CD46 receptor density determines preferential killing of tumor cells by oncolytic measles virus. Cancer Res 2004, 64(14):4919-4926.

30. Dhiman N, Jacobson RM, Poland GA: Measles virus receptors: SLAM and CD46. Rev Med Virol 2004, 14(4):217-229.

31. Russell S: CD46: a complement regulator and pathogen receptor that mediates links between innate and acquired immune function. Tissue Antigens 2004, 64(2):111-118.

32. Jurianz K, Ziegler S, Garcia-Schüler H, Kraus S, Bohana-Kashtan O, Fishelson Z, Kirschfink M: Complement resistance of tumor cells: basal and induced mechanisms. Mol Immunol 1999, 36(13-14):929-939.
33. Peng KW, Facteau S, Wegman T, O'Kane D, Russell SJ: Noninvasive in vivo monitoring of trackable viruses expressing soluble marker peptides. Nat Med 2002, 8(5):527-531.

34. Dingli D, Russell SJ, Morris JC 3rd: In vivo imaging and tumor therapy with the sodium iodide symporter. J Cell Biochem 2003, 90(6):1079-1086.

35. Radecke F, Spielhofer P, Schneider H, Kaelin K, Huber M, Dotsch C Christiansen G, Billeter MA: Rescue of measles viruses from cloned DNA. EMBO J 1995, 14(23):5773-5784.

36. Parks CL, Lerch RA, Walpita P, Wang HP, Sidhu MS, Udem SA: Comparison of predicted amino acid sequences of measles virus strains in the Edmonston vaccine lineage. J Virol 2001, 75(2):910-920.

37. Geevarghese SK, Geller DA, de Haan HA, et al: Phase I/II study of oncolytic herpes simplex virus NV1020 in patients with extensively pretreated refractory colorectal cancer metastatic to the liver. Hum Gene Ther 2010, 21(9):1119-1128.

38. Lolkema MP, Arkenau HT, Harrington $\mathrm{K}$, et al: A phase I study of the combination of intravenous reovirus type 3 Dearing and gemcitabine in patients with advanced cancer. Clin Cancer Res 2011, 17(3):581-588.

39. Chang JF, Chen PJ, Sze DY, et al: Oncolytic virotherapy for advanced liver tumors. J Cell Mol Med 2009, 13(7):1238-1247.

40. Wagner F, Henningsen B, Lederer C, Eichenmüller M, Gödeke J: MüllerHöcker J. Schweinitz DV: Kappler R. Rapamycin blocks hepatoblastoma growth in vitro and in vivo implicating new treatment options in high-risk patients. Eur J Cancer; 2012

41. Kirn DH, Thorne SH: Targeted and armed oncolytic poxviruses: a novel multi-mechanistic therapeutic class for cancer. Nat Rev Cancer 2009, 9:64-71.

42. Russell SJ, Peng KW: Measles virus for cancer therapy. Curr Top Microbiol Immunol 2009, 330:213-241.

43. Tatsuo H, Ono N, Tanaka K, Yanagi Y: SLAM (CDw150) is a cellular receptor for measles virus. Nature 2000, 406(6798):893-897.

44. Noyce RS, Bondre DG, Ha MN, Lin LT, Sisson G, Tsao MS, et al: Tumor cell marker PVRL4 (nectin 4) is an epithelial cell receptor for measles virus. PLoS Pathog 2011, 7:e1002240.

45. Mühlebach MD, Mateo M, Sinn PL, Prüfer S, Uhlig KM, Leonard VH, et al: Adherens junction protein nectin 4 is the epithelial receptor for measles virus. Nature 2011, 480:530-533.

46. Sato $\mathrm{H}$, Yoneda $\mathrm{M}$, Honda $\mathrm{T}$, Kai C: Morbillivirus receptors and tropism: multiple pathways for infection. Front Microbio/ 2012, 3:75.

47. Watanabe A, Yoneda M, Ikeda F, Terao-Muto Y, Sato H, Kai C: CD147/ EMMPRIN acts as a functional entry receptor for measles virus on epithelial cells. J Virol 2010, 84:4183-4193.

48. Eicher C, Dewerth A, Kirchner B, Warmann SW, Fuchs J, Armeanu-Ebinger S: Treatment effects of the multikinase inhibitor sorafenib on hepatoblastoma cell lines and xenografts in NMRI-Foxn1 nu mice. Liver Int 2012, 32(4):574-581

49. Servet-Delprat C, Vidalain PO, Azocar O, Le Deist F, Fischer A, RabourdinCombe C: Consequences of Fas-mediated human dendritic cell apoptosis induced by measles virus. J Virol 2000, 74(9):4387-4393.

50. Toth AM, Devaux P, Cattaneo R, Samuel CE: Protein kinase PKR mediates the apoptosis induction and growth restriction phenotypes of $C$ proteindeficient measles virus. J Virol 2009, 83(2):961-968.

51. Esolen LM, Park SW, Hardwick JM, Griffin DE: Apoptosis as a cause of death in measles virus-infected cells. J Virol 1995, 69(6):3955-3958.

52. Wodarz D: Viruses as antitumor weapons: defining conditions for tumor remission. Cancer Res 2001, 61:3501-3507.

53. Coffey MC, Strong JE, Forsyth PA, Lee PW: Reovirus therapy of tumors with activated Ras pathway. Science 1998, 282:1332-1334.

54. Nemunaitis J, Ganly I, Khuri F, Arseneau J, Kuhn J, McCarty T, et al: Selective replication and oncolysis in p53 mutant tumors with ONYX-015, an E1B$55 \mathrm{kD}$ gene-deleted adenovirus, in patients with advanced head and neck cancer: a phase II trial. Cancer Res 2000, 60:6359-6366.

doi:10.1186/1471-2407-12-427

Cite this article as: Zhang et al:: Engineered measles virus Edmonston strain used as a novel oncolytic viral system against human hepatoblastoma. BMC Cancer 2012 12:427. 